\title{
Infiltração de atrazina em Latossolo submetido aos sistemas de plantio direto e convencional
}

\author{
Fabio Veríssimo Correia ${ }^{(1)}$, Fabio Martins Mercante ${ }^{(2)}$, Amoacy Carvalho Fabrício(2), \\ Tácio Mauro Pereira de Campos $^{(3)}$, Eurípedes Amaral Vargas Júnior ${ }^{(3)}$ e Tomaz Langenbach ${ }^{(1)}$
}

(1)Universidade Federal do Rio de Janeiro, Instituto de Microbiologia Prof. Paulo de Góes, CCS Bloco I, Cidade Universitária, Ilha do Fundão, CEP 21941-590 Rio de Janeiro, RJ. E-mail: fabioverissimobr@yahoo.com.br, tomazlange@yahoo.com.br (2)Embrapa Agropecuária Oeste, BR 163, Km 253,6, Caixa Postal 661, CEP 79804-970 Dourados, MS. E-mail: mercante@cpao.embrapa.br, amoacy@cpao.embrapa.br (3)Pontifícia Universidade Católica do Rio de Janeiro, Dep. de Engenharia Civil, Lab. de Geotecnia Ambiental, CEP 22455-900 Rio de Janeiro, RJ. E-mail: tacio@civ.puc-rio.br, vargas@civ.puc-rio.br

\begin{abstract}
Resumo - O objetivo deste trabalho foi comparar a lixiviação e o potencial de contaminação de lençóis de água com atrazina, em solos sob manejo de plantio direto (PD) e convencional (PC). Foram realizados experimentos em campo e em colunas com Latossolo Vermelho-Escuro distroférrico, submetido ao manejo PD e PC, em Dourados, MS, Brasil. Os valores de condutividade hidráulica e potencial mátrico, determinados com o permeâmetro de Guelph no PD, demonstram fluxo contínuo de água no solo. A maior condutividade na superfície, associada ao potencial mátrico negativo, demonstrou descontinuidade hidrológica, na comparação das camadas subjacentes, verificada no PC em relação ao PD. No entanto, o PD apresentou deslocamento vertical de atrazina menor que o PC. Os resultados mostraram que as perdas de atrazina por lixiviação ocorreram mais intensamente com as primeiras chuvas, logo após a aplicação do produto. O PD apresentou maior concentração de atrazina em comparação ao PC, tendo reduzido as perdas por lixiviação. Os dados indicam que a tecnologia de plantio direto pode reduzir o impacto ambiental provocado pelos pesticidas.
\end{abstract}

Termos para indexação: poluição do solo, lixiviação, herbicida, permeabilidade.

\section{Infiltration of atrazine in an Oxisol under no-tillage and conventional tillage}

\begin{abstract}
The aim of this work was to compare leaching and potential groundwater contamination in soil under no-tillage and conventional tillage. This experiment was carried out in field conditions and soil columns, using an Oxisol under no-tillage (NT) and conventional tillage (CT) systems in Dourados, MS, Brazil. The determination of the hydraulic conductivity and matrix flux potential, with the use of a Guelph permeameter in the NT, showed a continue flow of water into the soil. Greater conductivity found in the surface soil, associated with the negative matrix flux potential, showed the discontinued hydraulic conductivity, when comparing subsurface layers, in the $\mathrm{CT}$ in relation to NT. However, NT resulted in less vertical displacement of atrazine than CT. The largest atrazine losses by leaching occurred more intensely after the first rainfall that followed the product application. Greater atrazine concentrations were retained in NT soil than in CT soil. This resulted in low levels of leaching from the NT soil, which indicates that no-tillage technology can reduce the environmental impact of pesticides.
\end{abstract}

Index terms: soil pollution, leaching, herbicide, permeability.

\section{Introdução}

A dinâmica do desempenho dos herbicidas em solos submetidos ao plantio direto ou em outras práticas de manejo conservacionista é pouco conhecida, apesar dos avanços no estudo sobre pesticidas em ambientes tropicais (Langenbach et al., 2000, 2001).
A relação entre plantio direto e herbicidas compreendia um acréscimo de aplicação pós-colheita, com o objetivo de promover a morte das plantas. Recentemente, para a redução no uso de pesticidas neste sistema de manejo, desenvolveram-se espécies de plantas de cobertura com diferentes ciclos vegetativos que permitem o acamamento mecânico (Argenta et al., 2001; Oliveira et al., 2001). 
A adoção do plantio direto promove mudanças em muitas características do solo no decorrer dos anos de cultivo (Six et al., 2002). A infiltração da água em solos sob plantio direto (PD) tende a aumentar em comparação aos solos submetidos ao plantio convencional (PC) (Edwards et al., 1988). Propriedades como porosidade, teor de matéria orgânica e atividade microbiana também são afetadas e exercem influência no destino de pesticidas no solo (Scheunert, 1992a, 1992b).

$\mathrm{O}$ estudo dos efeitos dos sistemas de manejo sobre a dinâmica de herbicidas apresenta resultados controversos. O aumento da mobilidade dessas substâncias no PD tem sido atribuído à redução na evaporação e aumento do fluxo preferencial em canais formados pelas raízes e macroporos (Singh et al., 2002). Por sua vez, alguns autores citam que a cobertura vegetal morta depositada sobre os solos submetidos ao PD funciona como barreira de retenção de herbicidas, diminuindo assim o potencial de lixiviação (Langenbach et al., 2001).

Este trabalho utilizou o herbicida atrazina como modelo, por se tratar de um dos maiores poluidores do lençol d'água em diversos países (Caspel \& Larson, 2001). A atrazina (2-cloro-4-etilamino-6-isopropilamino-striazina) é um herbicida da família das s-triazinas utilizado no controle de plantas daninhas, principalmente de dicotiledôneas de folhas largas, no cultivo de milho, sorgo, cana-de-açúcar, abacaxi, entre outros. Estudos têm demonstrado a contaminação do solo, águas superficiais e subterrâneas por este produto (Kolpin et al., 2000; Hamilton \& Miller, 2002). Em alguns desses estudos, a contaminação excede os limites estabelecidos para água potável nos EUA e Europa (Struthers et al., 1998). A maioria das investigações sobre a dinâmica de pesticidas tem sido conduzida em países de clima temperado, predominantemente na Europa e América do Norte, e há uma lacuna no conhecimento sobre a influência do manejo do plantio direto nos processos de lixiviação e degradação dos pesticidas em países de clima tropical como o Brasil (Langenbach et al., 2000, 2001).

O objetivo deste trabalho foi avaliar a lixiviação de atrazina em Latossolo sob plantio direto (PD) e plantio convencional (PC) em experimento de campo e em colunas de solo indeformado.

\section{Material e Métodos}

O solo utilizado nos experimentos foi um Latossolo Vermelho distroférrico típico, de textura muito argilosa, oriundo do Município de Dourados, MS (22 ${ }^{\circ} 14$ 'S e $\left.54^{\circ} 49^{\prime} \mathrm{W}\right)$. A descrição físico-química do solo, determinada pelo Laboratório de Análise de Solo da Embrapa Agropecuária Oeste, apresentou $100 \mathrm{~g} \mathrm{~kg}^{-1} \mathrm{de}$ areia, $110 \mathrm{~g} \mathrm{~kg}^{-1}$ de silte e $790 \mathrm{~g} \mathrm{~kg}^{-1}$ de argila. $\mathrm{O}$ pH em água 6,0 , a matéria orgânica $31 \mathrm{~g} \mathrm{~kg}^{-1}$ no $\mathrm{PC}$ e $33 \mathrm{~g} \mathrm{~kg}^{-1}$ no PD.

Os tratamentos correspondentes aos diferentes sistemas de manejo do solo foram dispostos em faixas, num ensaio conduzido no campo experimental da Embrapa Agropecuária Oeste, implantado em 1995. Os sistemas intensivos de produção avaliados consistiram em manejo sob plantio convencional (aração e gradagem) e o sistema plantio direto, ambos cultivados com milho. Informações adicionais sobre os sistemas de produção podem ser encontradas em Silva et al. (2006).

Os ensaios de permeabilidade de campo foram realizados com o permeâmetro de Guelph (PG), fabricado pela Soil Moisture Inc., medindo a permeabilidade de campo saturada $\left(\mathrm{K}_{\mathrm{fs}}\right)$ entre $10^{-2}$ e $10^{-6} \mathrm{~cm} \mathrm{~s}^{-1}$ e o potencial mátrico do solo $\left(\Psi_{\mathrm{m}}\right)$ (Reynolds \& Elrick, 1985 , 1986). O método utiliza o princípio de Mariotte para estabelecer e manter o nível de água e medir a recarga correspondente.

As medições foram realizadas em cada manejo (PD e PC), nas profundidades de 20 e de $60 \mathrm{~cm}$ e nas alturas de carga d'água de 5 e de $10 \mathrm{~cm}$. A avaliação foi realizada nas linhas e nas entrelinhas de plantio, a fim de verificar o efeito do sistema radicular sobre a permeabilidade. Foram realizadas 20 repetições por manejo, sendo 10 na linha e 10 na entrelinha. Uma descrição completa do modo de operação do PG pode ser encontrada no site da Soil Moisture Equipment Corporation (1991). Durante a execução do experimento de campo, os dados do índice pluviométrico de dezembro de 2002 a março de 2003 foram coletados na estação meteorológica da Embrapa Agropecuária Oeste.

As áreas sob PD e PC cultivadas com milho foram tratadas com atrazina (produto comercial Gesaprim 500) na dose recomendada de $6 \mathrm{~L} \mathrm{ha}^{-1}\left(3 \mathrm{~L} \mathrm{ha}^{-1}\right.$ i.a.), na pósemergência da cultura. No 1으, 7으, 15으, 30oe 60o dia após a aplicação do herbicida, foram coletadas amostras de solo em ambos os manejos. A coleta por área foi realizada de forma inteiramente casualizada, com três repetições em cada tempo de amostragem, quando foram abertas trincheiras para as coletas das amostras de solo de $5 \mathrm{em} 5 \mathrm{~cm}$ até a profundidade de $1 \mathrm{~m}$. Uma amostra composta de solo de $200 \mathrm{~g}$ foi preparada com três subamostras coletadas de cada camada. 
Foram pesados $50 \mathrm{~g}$ de solo em erlenmeyer e adicionados $100 \mathrm{~mL}$ de acetona p.a. A suspensão foi agitada durante 20 minutos a $100 \mathrm{rpm}$ em agitador orbital e tratada com banho de ultra-som (Elma/Transsonic, $1,4 \mathrm{~A}, 35 \mathrm{kHz}$ ) durante 10 minutos para extração dos resíduos de atrazina. Em seguida, foi filtrada em papelfiltro Whatman no 2 e transferida para balão volumétrico, onde foi concentrada até a secura no evaporador rotativo a $35^{\circ} \mathrm{C}$. A amostra foi ressuspendida em $100 \mathrm{~mL}$ de solução metanol:água $(85: 15 \mathrm{v} / \mathrm{v})$ e transferida para um funil de decantação, onde se efetuou a purificação com a adição de $30 \mathrm{~mL}$ de diclorometano. Após a agitação do funil e decantação, a fração inferior (diclorometano) foi separada. $\mathrm{O}$ sobrenadante contido no funil foi tratado mais duas vezes sucessivamente com diclorometano conforme descrito.

Todas as frações de diclorometano foram reunidas e concentradas no evaporador rotativo. Em seguida, o extrato foi ressuspendido em $10 \mathrm{~mL}$ de metanol. Dessa porção, foi retirada uma alíquota de $2 \mathrm{~mL}$, que foi concentrada no evaporador rotativo até aproximadamente $0,5 \mathrm{~mL}$, e aplicada em seguida numa coluna reversa de $\mathrm{C}_{18}$ (extrator de fase sólida) previamente ativada com metanol. A amostra da coluna foi eluída com $5 \mathrm{~mL}$ de água e o volume percolado foi descartado. Posteriormente, foram adicionados 5,0 mL de solução diclorometano:metanol $(7: 3 \mathrm{v} / \mathrm{v})$, cujo eluato que continha os resíduos foi recolhido em balão volumétrico, concentrado no evaporador rotativo e ressuspendido com $5,0 \mathrm{~mL}$ de solução acetonitrila:água $(8: 2 \mathrm{v} / \mathrm{v})$ para obtenção do extrato de solo (Correia \& Langenbach, 2006).

A análise dos resíduos de atrazina em cromatografia líquida de alta eficiência (HPLC) foi realizada no extrato de solo filtrado em membrana $(0,22 \mu \mathrm{m}$ - Millipore GV Millex/polietileno), injetado no HPLC Waters 600 e medido no detector UV em $254 \mathrm{~nm}$, após separação em coluna de fase reversa $\mathrm{RP}_{8}(5 \mu \mathrm{m}, 250 \times 4 \mathrm{~mm})$. A corrida foi efetuada em fase móvel de metanol: água deionizada em dois gradientes de concentração $(65: 35 \mathrm{v}: \mathrm{v}$, $50: 50 \mathrm{v}: \mathrm{v})$, a fim de evitar falsos resultados decorrentes de impurezas. A coluna foi mantida em temperatura de $21^{\circ} \mathrm{C}$, com o fluxo da fase móvel de $0,5 \mathrm{~mL} \mathrm{~min}^{-1}$. Todas as amostras foram analisadas sob estas condições com o volume de injeção de $20 \mu \mathrm{L}$.

Em tubos de PVC de $30 \mathrm{~cm}$ de altura e $15 \mathrm{~cm}$ de diâmetro, foram coletadas amostras indeformadas nas áreas sobre os sistemas de plantio convencional (PC) e plantio direto $(\mathrm{PD})$. Foram realizadas quatro repetições por área, escolhidas aleatoriamente em diferentes pontos e transportadas para o laboratório para montagem das colunas de solo. Antes do início do experimento, os tubos contendo os solos foram acondicionados, saturando-se por capilaridade cada um deles com água durante uma semana para padronizar o teor de umidade. Após uma semana de repouso, efetuou-se a aplicação de ${ }^{14} \mathrm{C}$-atrazina.

$\mathrm{O}$ experimento foi conduzido em laboratório, à temperatura ambiente variando entre a mínima de $23^{\circ} \mathrm{C}$ e a máxima de $32^{\circ} \mathrm{C}$. A partir do segundo dia após aplicação de ${ }^{14} \mathrm{C}$-atrazina, aplicou-se água duas vezes por semana, distribuindo-a homogeneamente sobre a superfície do solo, simulando o índice pluvial de verão (200 mm por mês). A coluna permitiu a drenagem livre do lixiviado, que foi coletado duas vezes por semana. Logo após a simulação da chuva, por meio de um funil e frascos de $500 \mathrm{~mL}$ acoplados logo abaixo das colunas, o lixiviado coletado foi acondicionado em refrigerador $\left(-4^{\circ} \mathrm{C}\right)$ durante dois dias para posterior extração de ${ }^{14} \mathrm{C}$-atrazina e determinação da radioatividade.

A molécula de ${ }^{14} \mathrm{C}$-atrazina foi purificada a $99 \%$ pela técnica de cromatografia de camada fina (TLC) com placa Merk (AL 20 × $20 \mathrm{~cm}$ Silicagel $60 \mathrm{~F}_{254}$ ), utilizandose como solvente a solução diclorometano:metanol $(95: 5 \mathrm{v}: \mathrm{v})$. A faixa da placa ocupada pela atrazina purificada foi recortada e eluída com acetona. $\mathrm{Na}$ aplicação da ${ }^{14} \mathrm{C}$-atrazina na superfície dos microcosmos, realizou-se diluição da radioatividade, adicionando-se $4.900 \mu \mathrm{L}$ de solução de atrazina comercial (Gesaprim 500) a $110 \mu \mathrm{L}$ de ${ }^{14} \mathrm{C}$-atrazina. Foram então aplicados homogeneamente, com a pipeta Hamilton, $300 \mu \mathrm{L}$ dessa solução na superfície de cada uma das colunas de solo. Ao final da aplicação, cada coluna de solo recebeu $33.300 \mathrm{~Bq}$ e a concentração de $3,0 \mathrm{~kg} \mathrm{ha}^{-1}$ de atrazina (i.a.), que representa a recomendação agronômica.

A radioatividade do lixiviado foi determinada, transferindo-se uma alíquota de $100 \mathrm{~mL}$ para um funil de decantação, onde se efetuou a extração com diclorometano, conforme descrito anteriormente, para purificação dos extratos de solo do experimento de campo. Em seguida, todas as frações de diclorometano foram reunidas, secadas no evaporador rotativo e, então, ressuspendidas em $10 \mathrm{~mL}$ de solução cintiladora (4 g difenil-ozalato [PPO]; 0,25 g 2,2-p-Penil-bis(5-feniloxazol) [POPOP]; $333 \mathrm{~mL}$ Triton X.100 e completada com tolueno até $1 \mathrm{~L}$ ) para determinação da radioatividade no cintilador Packard 2100. 
A radioatividade no solo foi medida apenas no final dos dois meses de experimento. O solo foi retirado do microcosmo e estratificado em camadas de $1 \mathrm{~cm}$ nos primeiros $5 \mathrm{~cm}$ superficiais. Nas camadas subjacentes até os $30 \mathrm{~cm}$ de profundidade, foram cortadas camadas de $5 \mathrm{em} 5 \mathrm{~cm}$. Cada camada foi secada ao ar, pesada e cuidadosamente homogeneizada. Três porções de cada camada de solo, entre 0,5 e $1 \mathrm{~g}$, foram pesadas em balança analítica e queimadas em Oxidizer Zinsser (Oximat 500). $\mathrm{O}^{14} \mathrm{CO}_{2}$ obtido da queima foi absorvido por um coquetel de cintilação líquida Aquasolv (1 L solução cintiladora $+666 \mathrm{~mL}$ metanol $+416 \mathrm{~mL}$ etanolamina) e a radioatividade, medida no cintilador Packard 2100. Os valores de dpm foram relacionados com a radioatividade total aplicada em cada microcosmo e expressos em porcentagem.

Os dados de avaliação do comportamento da atrazina nos dois tipos de manejo foram interpretados por meio de análise de variância. As médias foram comparadas, utilizando-se o teste de Newman-Keuls, a 5\% de probabilidade.

\section{Resultados e Discussão}

Valores de $\mathrm{K}_{\mathrm{fs}}$ e $\Psi_{\mathrm{m}}$ obtidos na linha de cultivo e na entrelinha com o permeâmetro de Guelph em condições de campo são iguais em ambos os sistemas de manejo (Tabela 1). Alguns autores sugerem que o desenvolvimento de raízes nas linhas de cultivo formam canais preferenciais para o fluxo da água, promovendo o aumento da condutividade nesta região (Singh et al., 2002). Entretanto, na interpretação dos resultados, essa hipótese não é verificada. Solos com valores de condutividade hidráulica saturada, na mesma faixa de ordem de grandeza, apresentam comportamentos de permeabilidade iguais (Reynolds \& Elrick, 1986).

$\mathrm{O}$ sistema PD apresentou valores menores de $\mathrm{K}_{\mathrm{fs}}$ aos $20 \mathrm{~cm}$ em relação aos obtidos nos $60 \mathrm{~cm}$ de profundidade.
O inverso foi observado no sistema PC, pois os maiores valores foram alcançados na superfície. $\mathrm{O}$ aumento do $\mathrm{K}_{\mathrm{fs}}$ na camada superficial no sistema PC pode ser devido ao revolvimento do solo pelos implementos agrícolas o que causa o rearranjo das partículas do solo na camada arável. A redução na movimentação do solo e o contínuo aporte de material vegetal na superfície do solo sob PD podem promover a formação de uma camada mais densa devido à supressão do material depositado.

A maior condutividade na superfície do solo no sistema PC pode representar, a princípio, aumento nas perdas do herbicida por lixiviação. Quando a quantidade de água da chuva excede a capacidade de infiltração do solo, começam as perdas por escoamento superficial. As perdas por escoamento superficial também podem ser intensificadas no sistema PC, quando a água que penetra no solo encontra uma camada mais adensada e com menor capacidade de infiltração, como observado neste trabalho. O acúmulo de umidade logo após pequenas precipitações promove em seguida o deslocamento horizontal da água, solo e herbicida (Reichenberger et al., 2007). A menor condutividade na superfície do PD aumenta o tempo de contato da atrazina com o solo, favorecendo o processo de adsorção e redução das perdas por lixiviação.

Os valores de $\mathrm{K}_{\mathrm{fs}}$ nos sistemas PD e PC foram semelhantes nos $60 \mathrm{~cm}$ de profundidade. Por se tratar de uma camada livre da ação dos implementos agrícolas, esta parte do perfil apresentou o mesmo comportamento quanto à condutividade de água no solo.

Outro aspecto que precisa ser observado é a continuidade no fluxo de água no perfil do solo. O fato de o sistema PC apresentar maior condutividade na superfície não garante que se trate de um sistema mais eficiente quanto ao abastecimento do lençol d'água. O fluxo de água responde ao gradiente de potencial no solo. Se o gradiente vertical for pequeno, haverá pouco

Tabela 1. Valores de condutividade hidráulica saturada $\left(\mathrm{K}_{\mathrm{fs}}, \mathrm{em} \mathrm{cm} \mathrm{h}^{-1}\right)$ e potencial mátrico $\left(\Psi_{\mathrm{m}}\right.$, em $\left.\mathrm{cm}\right)$, nas profundidades de 20 e $60 \mathrm{~cm}$, nas linhas e entrelinhas, dos solos sob plantio direto ( PD) e plantio convencional (PC), em condições de campo ${ }^{(1)}$.

\begin{tabular}{|c|c|c|c|c|c|c|c|c|}
\hline \multirow[t]{3}{*}{ Sistema } & \multicolumn{4}{|c|}{ Linhas } & \multicolumn{4}{|c|}{ Entrelinhas } \\
\hline & \multicolumn{2}{|c|}{$20 \mathrm{~cm}$} & \multicolumn{2}{|c|}{$60 \mathrm{~cm}$} & \multicolumn{2}{|c|}{$20 \mathrm{~cm}$} & \multicolumn{2}{|c|}{$60 \mathrm{~cm}$} \\
\hline & $\mathrm{K}_{\mathrm{fs}}$ & $\Psi_{\mathrm{m}}$ & $\mathrm{K}_{\mathrm{fs}}$ & $\Psi_{\mathrm{m}}$ & $\mathrm{K}_{\mathrm{fs}}$ & $\Psi_{\mathrm{m}}$ & $\mathrm{K}_{\mathrm{fs}}$ & $\Psi_{\mathrm{m}}$ \\
\hline$\overline{\mathrm{PD}}$ & $\begin{array}{c}8,8 \mathrm{E}-05 \mathrm{Aa} \pm \\
1,000 \mathrm{E}-04\end{array}$ & $\begin{array}{c}2,18 \mathrm{E}-02 \mathrm{~b} \pm \\
0,00028\end{array}$ & $\begin{array}{c}4,22 \mathrm{E}-04 \mathrm{Aa} \pm \\
0,00012\end{array}$ & $\begin{array}{c}2,43 \mathrm{E}-04 \mathrm{Bb} \pm \\
4.900 \mathrm{E}-06\end{array}$ & $\begin{array}{c}8,84 \mathrm{E}-05 \mathrm{Aa} \pm \\
0,001\end{array}$ & $\begin{array}{c}2,18 \mathrm{E}-02 \mathrm{~b} \pm \\
0,0012\end{array}$ & $\begin{array}{c}4,22 \mathrm{E}-04 \mathrm{Aa} \pm \\
0,00013\end{array}$ & $\begin{array}{c}2,43 \mathrm{E}-04 \mathrm{Bb} \pm \\
2.330 \mathrm{E}-05\end{array}$ \\
\hline $\mathrm{PC}$ & $\begin{array}{c}1,27 \mathrm{E}-03 \mathrm{Aa} \pm \\
0,001\end{array}$ & Negativos & $\begin{array}{c}3,1 \mathrm{E}-04 \mathrm{Aa} \pm \\
0,0002\end{array}$ & $\begin{array}{c}2,79 \mathrm{E}-04 \mathrm{Bc} \pm \\
2,100 \mathrm{E}-06\end{array}$ & $\begin{array}{c}1,21 \mathrm{E}-03 \mathrm{Aa} \pm \\
0,00014\end{array}$ & Negativos & $\begin{array}{c}3,1 \mathrm{E}-04 \mathrm{Aa} \pm \\
1,000 \mathrm{E}-04 \\
\end{array}$ & $\begin{array}{c}2,79 \mathrm{E}-04 \mathrm{Bc} \pm \\
7,100 \mathrm{E}-06\end{array}$ \\
\hline
\end{tabular}

(1)Valores representam médias $(\mathrm{n}=10) \pm \mathrm{DPM}$ (desvio-padrão da média); médias seguidas da mesma letra, maiúscula na coluna e minúscula na linha, em cada profundidade, não diferem entre si pelo teste de Newman-Keuls, a $5 \%$ de probabilidade. 
fluxo de água mesmo com elevados valores de condutividade. Os valores de $\Psi_{\mathrm{m}}$ no sistema PD nas profundidades de 20 e $60 \mathrm{~cm}$ indicam fluxo contínuo de água no solo, pois garantem um gradiente potencial se deslocando do local de maior para menor energia da água. No PC os valores de $\Psi_{\mathrm{m}}$ foram negativos, indicando descontinuidade hidrológica, tipicamente causada pela estratificação do solo e desarranjo causado pelos implementos agrícolas. Ao comparar diferentes sistemas de manejo do solo e avaliar a infiltração de água no solo por meio de um permeâmetro de Guelph, Wu et al. (1992) observaram que, no sistema plantio direto, os poros conduzem água mais eficientemente do que no preparo convencional.

A estatística utilizada como ferramenta de análise de dados físico-hídricos do solo pode, em alguns casos, não corresponder ao comportamento ambiental. Gupta et al. (1993) realizaram estudo comparativo, em campo, da medida de condutividade hidráulica do solo saturado usando quatro métodos, e verificaram que as médias de condutividade hidráulica obtidas pelo método dos anéis concêntricos e pelo permeâmetro de Guelph foram estatisticamente iguais, entretanto, os dois diferiram entre si. Reynolds \& Elrick (1986) observaram que os valores de $\mathrm{K}_{\mathrm{fs}}$ na ordem de $10^{-5} \mathrm{~m} \mathrm{~s}^{-1}$ correspondem a meios porosos de alta permeabilidade, enquanto na ordem de $10^{-6} \mathrm{~m} \mathrm{~s}^{-1}$, a permeabilidade é intermediária. Os resultados deste trabalho, com diferentes valores de ordem de grandeza, mesmo considerados iguais, estatisticamente, apresentam comportamentos distintos em relação à condutividade hidráulica.

Com a finalidade de superar as limitações da estatística, trabalhos têm utilizado o índice calculado da relação entre duas condutividades avaliadas como análise do efeito do sistema de cultivo (Silva et al., 2003). Este índice $\left(\mathrm{K}_{20} \mathrm{~cm} /\right.$ $\mathrm{K}_{60} \mathrm{~cm}$ ) representa o grau de redução ou alteração da condutividade $K_{20} \mathrm{~cm}$ em relação à $K_{60} \mathrm{~cm}$. Nesta escala, quanto maior for o índice, maior será a condutividade na profundidade $20 \mathrm{~cm}$. Por meio desse recurso de análise, o plantio direto apresentou índice igual a 0,2 , enquanto o sistema convencional teve índice igual a 4. Estes resultados confirmam o significativo aumento da condutividade na superfície $(20 \mathrm{~cm})$ do PC e seus possíveis efeitos discutidos.

A atrazina aplicada inicialmente na superfície foi encontrada ao longo do perfil dos solos sob PD e PC, atingindo a profundidade de $1 \mathrm{~m}$ durante os 60 dias de experimento de campo (Figura 1). Em ambos os manejos observou-se nesse período diminuição gradativa da concentração de atrazina, principalmente na superfície e no total encontrado no solo. No $15^{\circ}$ dia após a aplicação, o PD apresentou distribuição da atrazina no solo diferente.
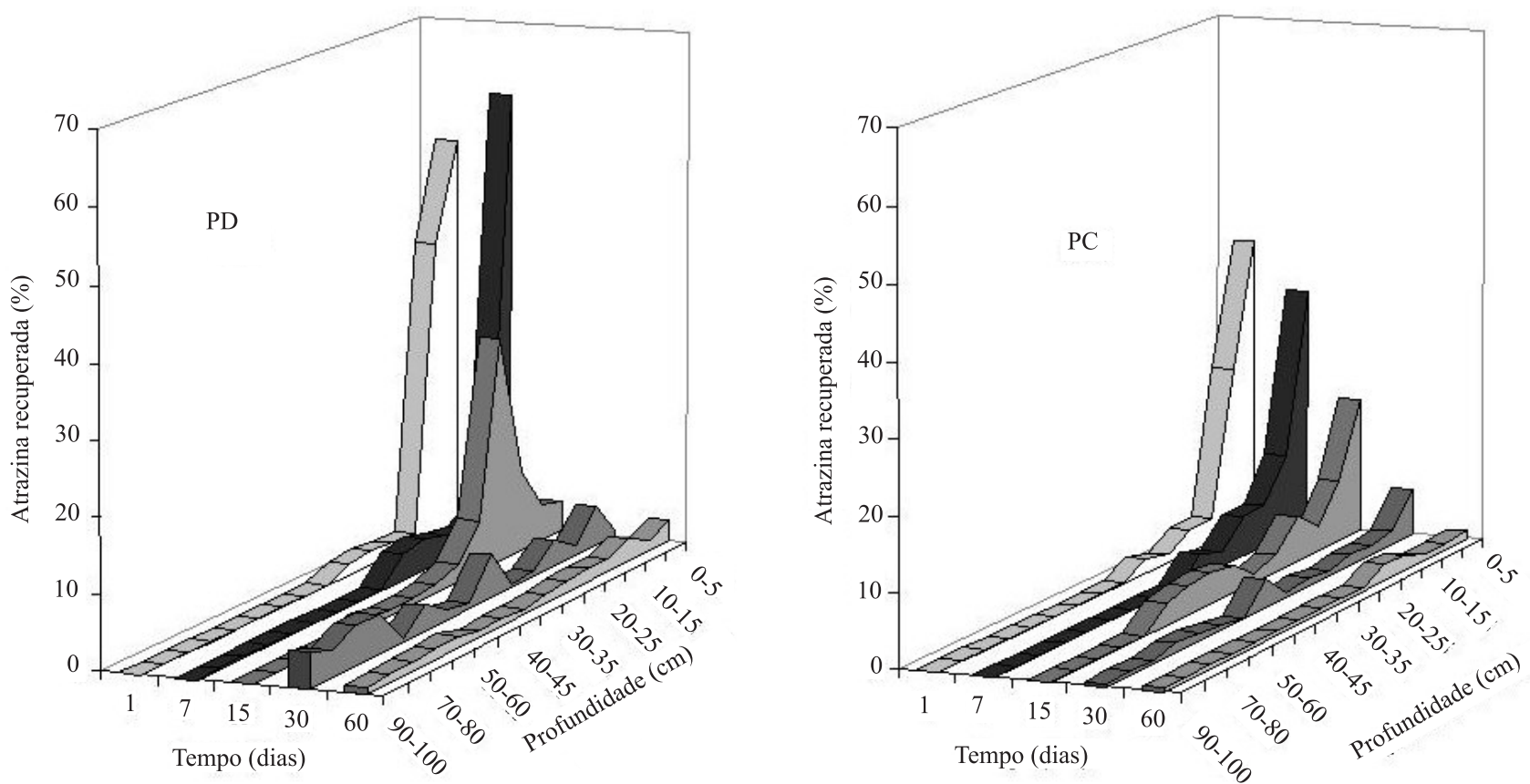

Figura 1. Distribuição da atrazina (\%) em diferentes profundidades dos solos sob plantio direto (PD) e plantio convencional (PC), em 60 dias de experimento. 
A maior concentração do herbicida na profundidade de 20 a $25 \mathrm{~cm}$ sugere que o PD retarda o processo de lixiviação e promove o deslocamento lento da atrazina, que se movimenta como uma onda. O movimento descendente da atrazina indica que uma parte não medida pode ter sido lixiviada para camadas mais profundas.

As porcentagens dos valores totais de atrazina recuperada (Tabela 2) mostram diferenças entre os manejos estudados. O solo sob PD apresenta maiores valores de atrazina recuperada em todos os tempos de amostragem em comparação ao solo sob PC. A diferença nos valores de atrazina recuperada devese, além da lixiviação para camadas não estudadas neste trabalho, a outros fatores como perda por volatilização, mineralização e formação de resíduos ligados nãoextraíveis do solo, parâmetros de difícil medição em experimentos de campo, que só podem ser feitos com ${ }^{14} \mathrm{C}$-atrazina em sistema fechado. Enquanto o herbicida permanece principalmente nas camadas superficiais do solo, está sujeito ao processo de adsorção, fenômeno intensificado no PD, quando se verifica o acúmulo de palha e matéria orgânica na superfície do solo. Os resultados dos ensaios com colunas de PVC também mostraram que a maior parte da atrazina aplicada se concentrou na superfície do solo sob PD (Figura 2).

Tabela 2. Totais porcentuais de atrazina recuperada do solo por extração com acetona nos sistemas plantio direto (PD) e convencional (PC) em condições de campo ${ }^{(1)}$.

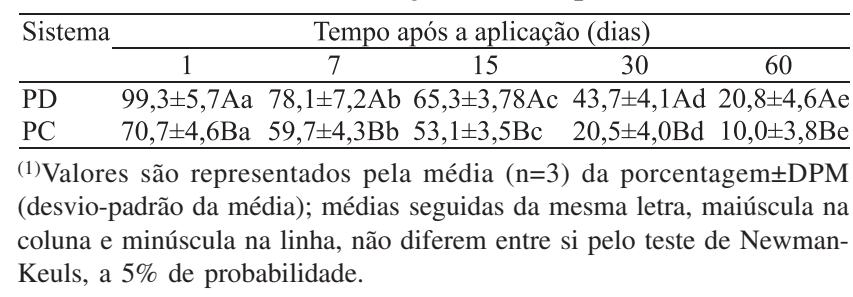

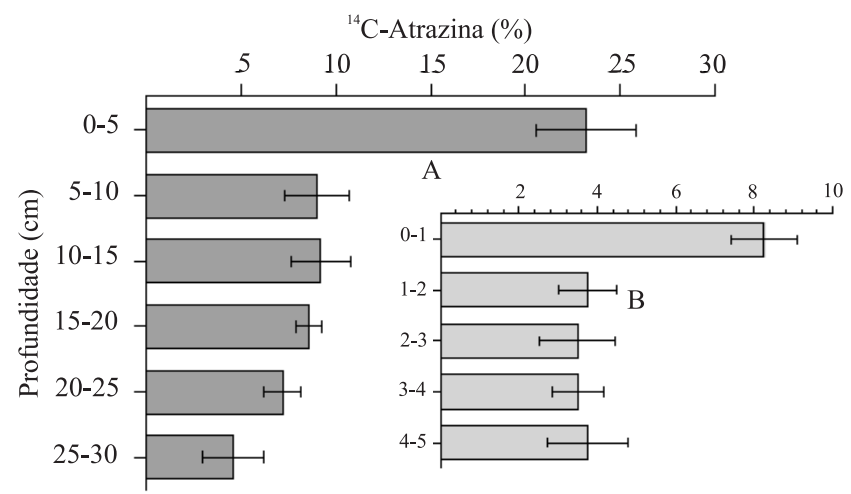

Figura 2. Distribuição porcentual de ${ }^{14} \mathrm{C}$-Atrazina no perfil do solo sob plantio direto: A) de 0 a $30 \mathrm{~cm}$, fatiados de $5 \mathrm{em} 5 \mathrm{~cm}$; B) de 0 a $5 \mathrm{~cm}$, fatiado de $1 \mathrm{em} 1 \mathrm{~cm}$. Os valores são representados pela média \pm DPM (desvio-padrão da média).
Apesar disso, observou-se a presença de pequenas concentrações de atrazina nas camadas menos superficiais $(45-100 \mathrm{~cm}) 30$ dias após a aplicação do herbicida em campo (Figura 1). Este fato pode ser explicado pela possibilidade de liberação da atrazina à medida que a palha vai sendo degradada (Gevao et al., 2000).

Os dados dos índices pluviométricos obtidos na estação meteorológica da Embrapa Agropecuária Oeste revelaram redução intensa na precipitação pluvial no período do experimento de campo. A precipitação em dezembro, janeiro, fevereiro e março foi, respectivamente, 190, 130, 117 e $48 \mathrm{~mm}$ por mês. Este comportamento na distribuição de chuvas tem sido observado desde 1997 devido a mudanças climáticas na região. Embora estas condições de estiagem promovam um estresse hídrico e mudanças no comportamento de pesticidas, o volume de chuva neste período não diminuiu os riscos de lixiviação nas camadas mais profundas do solo, pois o contaminante foi encontrado em todo perfil do solo estudado, seja sob PD como PC (Figura 1). O potencial de contaminação seria maior na ocorrência de chuvas torrenciais mais abundantes em torno de 200 a $300 \mathrm{~mm}$ por mês (Reichenberger et al., 2007).

Durante os 60 dias do experimento com colunas no laboratório, com a simulação de chuvas de $200 \mathrm{~mm}$ por mês, as perdas por lixiviação representaram um mecanismo importante no deslocamento da ${ }^{14} \mathrm{C}$-atrazina (Figura 3). Os resultados mostram que o PD e o PC

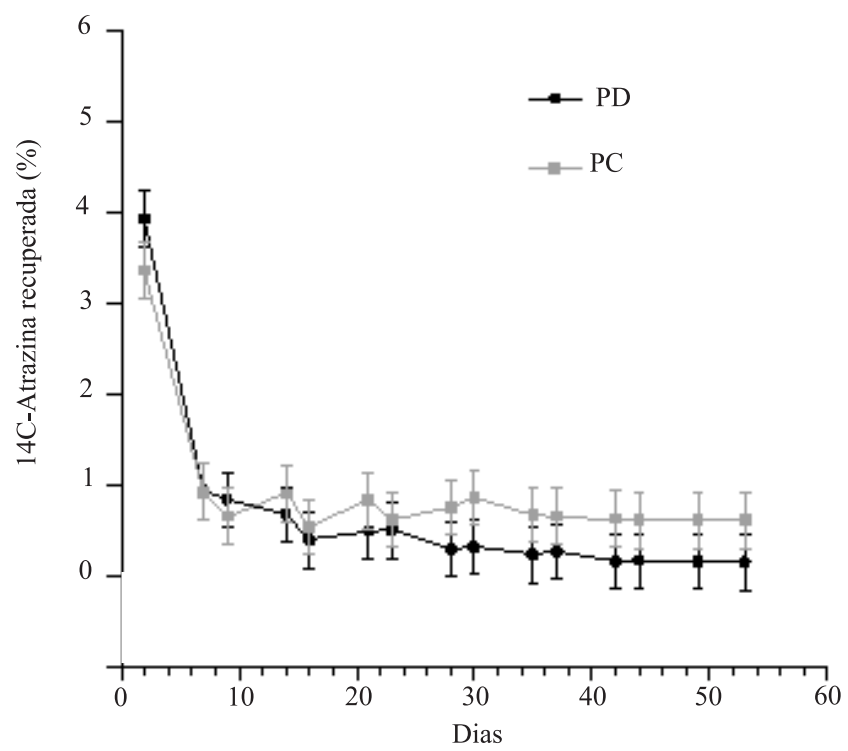

Figura 3. Porcentagem da ${ }^{14} \mathrm{C}$-Atrazina lixiviada das colunas de solo sob plantio direto (PD) e plantio convencional (PC). Os valores são representados pela média da porcentagem \pm EPM (erro-padrão da média). 
apresentaram valores altos de radioatividade no lixiviado logo no início da simulação de chuvas, reduzindo-se rapidamente após a segunda aplicação de água (3 dias) e permanecendo relativamente constante ao longo do experimento. As maiores perdas de atrazina têm sido correlacionadas com a primeira chuva ou irrigações após a aplicação do herbicida (Belamie \& Gouy, 1992; Patty et al., 1997; Correia et al., 2007). Quanto menor o tempo entre a aplicação do herbicida e a irrigação ou as chuvas, maiores são as perdas dos pesticidas por lixiviação.

A redução gradual nos teores de radioatividade no lixiviado dos diferentes sistemas pode ser resultado da progressiva adsorção destes produtos no solo com o passar do tempo (Gevao et al., 2000). No entanto, este processo não impede que o herbicida ao longo do tempo retorne à solução do solo pela dessorção, tornando-o suscetível ao processo de lixiviação.

Os porcentuais totais de lixiviado em relação ao aplicado no PC e PD foram, respectivamente, de $13 \mathrm{e}$ $9 \%$. Ao estudar o efeito da intensidade da chuva na distribuição e transporte de herbicidas, Sigua et al. (1995) observaram que a lixiviação foi dependente da quantidade e da duração da simulação da chuva. Este trabalho poderia apresentar maiores perdas do herbicida por lixiviação, promovida pela maior intensidade da simulação de chuva ou o aumento da duração do experimento.

As porcentagens de radioatividade presentes nos solos após os 60 dias de experimento são apresentadas nas Figuras 2 e 4 . A distribuição do herbicida no perfil do

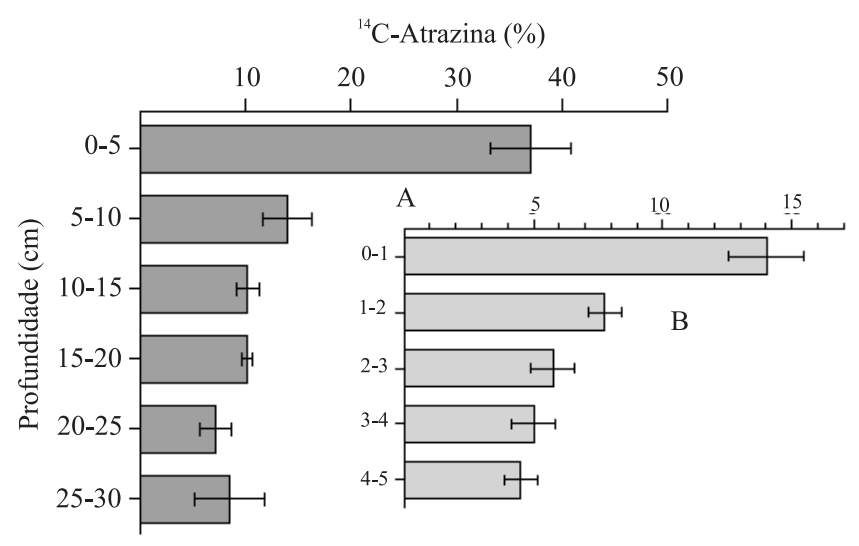

Figura 4. Distribuição porcentual de ${ }^{14} \mathrm{C}$-Atrazina no perfil do solo sob plantio convencional: A) de 0 a $30 \mathrm{~cm}$, fatiados de $5 \mathrm{em} 5 \mathrm{~cm}$; B) de 0 a $5 \mathrm{~cm}$, fatiado de $1 \mathrm{em} 1 \mathrm{~cm}$. Os valores são representados pela média \pm DPM (desvio-padrão da média). solo mostra que houve um movimento descendente a partir da sua aplicação na superfície do solo, em ambos os sistemas de manejo, comportamento este confirmado pelas concentrações do produto encontrado no lixiviado (Tabela 3) e sua distribuição no experimento de campo. Os valores totais de radioatividade recuperados no solo foram 77 e $60 \%$ para os sistemas PC e PD, respectivamente.

A distribuição de radioatividade nos solos sob PD e PC, em ambos os sistemas, apresentou maior concentração da atrazina nos primeiros $5 \mathrm{~cm}$ (PD 23\% e PC 37\%) e o deslocamento progressivo e decrescente até camadas mais profundas dos solos (Figuras 2 e 4). Porém, quanto à concentração nos primeiros $5 \mathrm{~cm}$, verificou-se que no PD a distribuição do herbicida foi mais homogênea. Este comportamento pode ser resultado das modificações promovidas pelo PD no solo. Autores têm sugerido que práticas de manejo conservacionistas como o PD promovem a melhoria na estrutura do solo na formação de agregados. A formação de agregados maiores está diretamente ligada à existência de macroporos, aumentando o potencial de permeabilidade e, conseqüentemente, o fluxo de água e herbicida para camadas mais profundas (Malone et al., 2003). Por sua vez, a melhoria na estrutura do solo decorre do efeito da matéria orgânica na formação desses agregados que, por sua vez, pode aumentar a retenção e diminuir a lixiviação do herbicida.

A maior concentração de radioatividade na camada superficial no PC pode ser decorrente do potencial de formação de selamento superficial nesse tipo de manejo. $\mathrm{O}$ uso intensivo de máquinas que promovem a degradação da estrutura e o rearranjo das partículas do solo no PC forma uma camada de selamento superficial, diminuindo a infiltração, mas aumentando a suscetibilidade às perdas por escoamento superficial logo após a aplicação. A relação entre as frações de partículas do solo e a formação de selamento superficial se evidencia quando a água é aplicada no solo sob a

Tabela 3. Porcentual de radioatividade recuperada da ${ }^{14} \mathrm{C}$-Atrazina no solo e no lixiviado do sistema plantio direto (PD) e convencional (PC) ${ }^{(1)}$.

\begin{tabular}{lcc}
\hline & PD & PC \\
\hline Lixiviado & 9,4 & 13,1 \\
Solo & 60 & 77 \\
\hline Total & $69,4 \pm 10$ & $90,1 \pm 9,8$ \\
\hline
\end{tabular}

${ }^{(1)}$ Os valores totais são médias ( $\left.\mathrm{n}=4\right) \pm$ DPM (desvio-padrão da média). 
forma de precipitação (Bosch \& Onstad, 1988; Reichert et al., 1992). Esta camada de selamento na superfície do solo ocorre principalmente no primeiro centímetro e reduz seu efeito rapidamente nas camadas subjacentes, permitindo assim uma lixiviação total maior, conforme observado nos resultados de condutividade hidráulica (Tabela 1).

Embora as porcentagens de atrazina perdida por lixiviação apresentem risco de contaminação dos lençóis d' água em ambos os manejos, o sistema de plantio direto foi mais eficiente que o plantio convencional na retenção, e diminuiu a dissipação desse herbicida no ambiente. Possivelmente isso ocorre também com outros pesticidas e, assim, o plantio direto seria a forma de manejo em que haveria uma mitigação da contaminação com agrotóxicos dos lençóis de água.

\section{Conclusões}

1. Os valores de condutividade hidráulica e potencial mátrico no sistema plantio direto demonstram um fluxo contínuo de água no solo; no preparo convencional do solo, a maior condutividade na superfície associada ao potencial mátrico negativo demonstra a descontinuidade hidrológica nas camadas subjacentes do solo.

2. O sistema plantio direto apresenta maior adsorção de atrazina no solo em comparação ao preparo convencional.

3. As maiores perdas de atrazina por lixiviação ocorrem logo após a sua aplicação com as primeiras simulações de chuva no sistema de plantio direto e preparo convencional do solo.

4. O sistema de plantio direto apresenta menor perda de atrazina por lixiviação comparado ao preparo convencional do solo.

\section{Agradecimentos}

Ao técnico Edir Martins Ferreira, pela colaboração na análise de resíduos; à Embrapa Agropecuária Oeste, por estabelecer as condições locais para os experimentos; à Syngenta, pelo fornecimento da molécula marcada com ${ }^{14} \mathrm{C}$ no anel da atrazina; ao $\mathrm{CNPq}$, à Fundação Universitária José Bonifácio e à Fundação Carlos Chagas Filho de Amparo à Pesquisa do Estado do Rio de Janeiro, pelo apoio financeiro.

\section{Referências}

ARGENTA, G.; SILVA, P.R.F. da; FLECK, N.G.; BORTOLINI, C.G.; NEVES, R.; AGOSTINETTO, D. Efeitos do manejo mecânico e químico da aveia-preta no milho em sucessão e no controle do capim-papuã. Pesquisa Agropecuária Brasileira, v.36, p.851-860, 2001.

BELAMIE, R.; GOUY, V. Introduction des pollutants dans le milieu fluvial. Influence du ruissellement des sols. Oceanis, v.18, p.505521, 1992.

BOSCH, D.D.;ONSTAD, C.A. Surface seal hydraulic conductivity as affected by rainfall. Transactions of the ASAE, v.31, p.11201127, 1988.

CASPEL, P.D.; LARSON, S.J. Effect of scale on the behavior of atrazine in surface waters. Environmental Science and Technology, v.35, p.648-657, 2001.

CORREIA, F.V.; LANGENBACH, T. Dinâmica da distribuição e degradação de atrazina em argissolo Vermelho-Amarelo sob condições de clima tropical úmido. Revista Brasileira de Ciência do Solo, v.30, p.183-192, 2006.

CORREIA, F.V.; MACRAE, A.; GUILHERME, L.R.G.; LANGENBACH, T. Atrazine sorption and fate in a Ultisol from humid tropical Brazil. Chemosphere, v.67, p.847-854, 2007.

EDWARDS, W.M.; NORTON, L.D.; REDMOND, C.E. Characterizing macropores that affects infiltration into non-tilled soil. Soil Science Society of American Journal, v.52, p.483-487, 1988.

GEVAO, B.; SEMPLE, K.T.; JONES, K.C. Bound pesticide residues in soils: a review. Environmental Pollution, v.108, p.3-14, 2000.

GUPTA, R.K.; RUDRA, R.P.; DICKINSON, W.T.; PATNI, N.K.; WALL, G.J. Comparison of saturated hydraulic conductivity measured by various field methods. Transaction of the ASAE, v.36, p.51-55, 1993.

HAMILTON, P.A.; MILLER, T.L. Lessons from the national waterquality assessment: a decade of intensive water-quality studies indicates that reducing diffuse nonpoint water contamination requires new tools and a holistic management approach. Journal of Soil and Water Conservation, v.57, p.16-22, 2002.

KOLPIN, D.W.; BARBASH, J.E.; GILLIOM, R.J. Pesticides in ground water of the United States, 1992-1996. Ground Water, v.38, p.858-863, 2000.

LANGENBACH, T.; SCHROLL, R.; PAIN, S. Fate and distribution of ${ }^{14} \mathrm{C}$-atrazine in a tropical Oxisol. Chemosphere, v.40, p.449$455,2000$.

LANGENBACH, T.; SCHROLL, R.; SCHEUNERT, I. Fate of the herbicide ${ }^{14} \mathrm{C}$-terbuthylazine in Brazilian soils under various climatic conditions. Chemosphere, v.45, p.387-398, 2001.

MALONE, R.W.; LOGSDON, S.; SHIPITALO, M.J.; WEATHERINGTON-RICE, J.; AHUJA, L.; MA, L. Tillage effect on macroporosity and herbicide transport in percolate. Geoderma, v.116, p.191-215, 2003.

OLIVEIRA, M.F.; ALVARENGA, R.C.; OLIVEIRA, A.C.; CRUZ, J.C. Efeito da palha e da mistura atrazine e metolachlor no controle 
de plantas daninhas na cultura do milho, em sistema de plantio direto. Pesquisa Agropecuaria Brasileira, v.36, p.37-41, 2001.

PATTY, L.; REAL, B.; GRILL, J.J. The use of grassed buffer strips to remove pesticides, nitrates and soluble phosphorus compounds from runoff water. Pesticide Science, v.49, p.243-251, 1997.

REICHENBERGER, S.; BACH, M.; SKITSCHAK, A.; FREDE, H.G. Mitigation strategies to reduce pesticide imputs into groundand surface-water and their effectiveness: a review. Science of the Total Environmental, v.384, p.1-35, 2007.

REICHERT, J.M.; VEIGA, M. da; CABEDA, M.S.V. Selamento superficial e infiltração de água em solos do Rio Grande do Sul. Revista Brasileira de Ciência do Solo, v.16, p.289-298, 1992.

REYNOLDS, W.D.; ELRICK, D.E. A method for simultaneous in situ measurement in the vadose zone of field saturated hydraulic conductivity, sorptivity and the conductivity-presure head relationship. Ground Water Monitoring Review, v.6, p.8495, 1986.

REYNOLDS, W.D.; ELRICK, D.E. Measurement of field-saturated hydraulic conductivity, sorptivity and the conductivity-pressure head relationship using the "Guelph permeameter". Soil Science, v.140, p.292-302, 1985.

SCHEUNERT, N. Physical and physico-chemical processes governing the residue behavior of pesticides in terrestrial ecosystems. In: EBING, W. (Ed.). Chemistry of plant Protection 8. Berlin: Springer-Verlag, 1992a. p.1-22.

SCHEUNERT, N. Transformation and degradation of pesticides in soil. In: EBING, W. (Ed.). Chemistry of Plant Protection 8. Berlin: Springer-Verlag:1992b. p.23-75.
SIGUA, G.C.; ISENSEE, A.R.; SADEGHI, A.M.; IM, G.J. Distribution and transport of atrazine as influenced by surface cultivation, earthworm population and rainfall pattern. Chemosphere, v.31, p.4237-4242, 1995.

SILVA, E.M; AZEVEDO, J.A.; RAUBER, J.C.; REATTO, A. Caracterização físico-hídrica e hidráulica de solos do bioma cerrado submetidos a diferentes sistemas de preparo. Planaltina: Embrapa Cerrados, 2003. 22p. (Boletim de Pesquisa e Desenvolvimento, n.101).

SILVA, R.F.; AQUINO, A.M.; MERCANTE, F.M.; GUIMARÃES, M.F. Macrofauna invertebrada do solo sob diferentes sistemas de produção em Latossolo da região do Cerrado. Pesquisa Agropecuária Brasileira, v.41, p.697-704, 2006.

SINGH, N.; KLOEPPEL, H.; KLEIN, W. Movement of metolachlor and terbuthylazine in core and packed soil columns. Chemosphere, v.47, p.409-415, 2002.

SIX, J.; FELLER, C.; DENEF, K.; OGLE, S.M.; SÁ, J.C.D.M.; ALBRECHT, A. Soil organic matter, biota and aggregation in temperate and tropical soils: effects of no-tillage. Agronomie, v.22, p.755-775, 2002.

SOIL MOISTURE EQUIPMENT CORPORATION. 2800 KI: operating instructions. Disponível em: http://www.soilmoisture.com/ PDF\%20Files/82800k1.pdf. Acesso em: 19 out. 2007.

STRUTHERS, J.K.; JAYACHANDRAN, K.; MOORMAN, T.B. Biodegradation of atrazine by Agrobacterium radiobacter $\mathrm{J} 14$ and use of this strain in bioremediation of contaminated soil. Applied Environmental Microbiology, v.64, p.3368-3375, 1998.

WU, L.; SWAN, J.B.; PAULSON, W.H.; RANDALL, G.W. Tillage effects on measured soil hydraulic properties. Soil Tillage Research, v.25, p.17-33, 1992.

Recebido em 29 de junho de 2007 e aprovado em 8 de outubro de 2007 